\title{
A Discriminant Analysis to Predict the Impact of Personality Traits, Self-esteem, and Time Spent Online on Different Levels of Internet Addiction Risk among University Students
}

\author{
Rocco Servidio \\ University of Calabria, Italy
}

\begin{abstract}
The aim of the current study is to evaluate the predictive influence of Big Five personality traits, self-esteem, and time spent online in discriminating among a sample of university students classified as normal, mildly, and moderately addicted Internet users. Self-report measures were administered to 207 Italian university students aged 19 to 41 years. Results indicated no severe Internet addiction among the participants, but only a mild and moderate risk. Correlation analysis revealed a significant negative association between Internet addiction score and self-esteem. The discriminant analysis indicated two main functions that allow discrimination in terms of the influence of personality traits, self-esteem, and time spent online in three groups of participants. These results may have valid implications in assessing students engaged in intensive online activities, indicating that tailored approaches to their problems are particularly important in preventing the risk of Internet addiction disorder.
\end{abstract}

Key words: Big Five personality, self-esteem, Internet addiction, university students, discriminant analysis

\section{Introduction}

The classification of Internet addiction as a behavioral disorder remains a controversial matter. It has been described as an individual's uncontrollable and compulsive use of the Internet, which negatively affects academic and job performances, reduces sleep and hygiene quality, and leads to reduced interpersonal social relationships (Lyvers, Karantonis, Edwards, \& Thorberg, 2016; Sahraian, Hedayati, Mani, \&

Correspondence concerning this article should be addressed to Rocco Servidio, University of Calabria, Department of Cultures, Education and Society, Via Pietro Bucci, Building Cube 20/B, 87036 Arcavacata di Rende, Cosenza, Italy. E-mail: rocco.servidio@unical.it

Received October 7, 2018
Hedayati, 2016; Young, 2015; Zhang et al., 2015). Furthermore, the conceptual model of Internet addiction incorporates tolerance, withdrawal, relapse, salience, conflict and mood modification as the core criteria for symptoms of addictive behavior (McNicol \& Thorsteinsson, 2017). On the basis of the current literature, the conceptualization of Internet addiction has been identified as an umbrella term, which includes a wide range of problematic online behavior (e.g., online gaming, online gambling, online sex, and social networking) and is characterized by extreme preoccupation with connecting to the Internet, with poor behavior control of online activities resulting in a negative impact on personal well-being and quality of life(Monacis, Sinatra, Griffiths, \& de Palo, 2018). Social media addiction is another recent kind of Internet addiction, which can be described as the inability to control oneself in the use of social networking sites (Andreassen, Pallesen, \& 
Griffiths, 2017; Błachnio et al., 2018). The adverse consequences of social media addiction, as a sub-type of behavioral addiction, includes distress in interpersonal relationships, as well as mental and problematic social behavior in several daily-life activities (Nie et al., 2019).

Recently, the new Diagnostic and Statistical Manual of Mental Disorders (DSM-5; American Psychiatric Association (APA, 2013)) has so far underlined the importance of including only Internet Gaming Disorder as a kind of emerging disturbance. It has been included in 'Section 3: Emerging Measures and Models' in order to better understand the nature of Internet addiction, and to possibly include it as a distinctive disorder in the next publication of DSM (Kuss, Griffiths, Karila, \& Billieux, 2014).

From the time Internet addiction was first described almost 20 years ago as a clinical disorder (Young, 1998), many studies - also done with university students - have subsequently been conducted on several psychological correlates (Al-Gamal, Alzayyat, \& Ahmad, 2016; Burnay, Billieux, Blairy, \& Larøi, 2015; Chou et al., 2015; Monacis, de Palo, Griffiths, \& Sinatra, 2017). On the other hand, other studies have focused, in relation to Internet addiction, on the following topics: personality traits and other risk factors (Kayiş et al., 2016; Li et al., 2017; Öztürk, Bektas, Ayar, Özgüven Öztornacı, \& Yağc1, 2015; Sahraian et al., 2016; Servidio, 2014); and overweight socially stigmatized adolescents (Gentile, Servidio, Caci, \& Boca, 2018).

Focusing on personality traits, the Big Five represents the classical theoretical model for categorizing a subject's individuality (Caprara, Barbaranelli, \& Borgogni, 2005; Costa \& McCrae, 1992). Concisely, this model identifies five dimensions in human personality traits: extraversion (reflecting expansiveness and energy), agreeableness (reflecting concern and politeness), conscientiousness (reflecting orderliness and precision), emotional stability (reflecting the capacity to cope with anxiety and emotionality), and openness (reflecting openness to novelty and interest towards different people and cultures).

A recent meta-analysis has examined 12 studies, which have found that all the Big Five personality traits are involved in Internet addiction (Kayiş et al., 2016). In particular, traits such as openness, conscientiousness, extraversion, and agreeableness were negatively associated with Internet addiction, whereas a positive correlation was observed with emotional stability. Apparently, the relationship between neuroticism and Internet addiction is stable, but one study indicated no statistical significance (Öztürk et al., 2015). In addition, the association between extraversion and Internet addiction is still controversial. Results from some studies demonstrated a positive relationship (Kuss, Shorter, van Rooij, van de Mheen, \& Griffiths, 2014; Zhou, Li, Li, Wang, \& Zhao, 2017), while another study reported a negative link (Yan, Li, \& Sui, 2014). Furthermore, a recent study revealed some significant relationships (Chwaszcz, Lelonek-Kuleta, Wiechetek, Niewiadomska, \& Palacz-Chrisidis, 2018). Similar incoherence has been found for openness to experiences. Servidio (2014) found a negative association between openness to experiences and Internet addiction, while another study reported a positive relationship (Hwang et al., 2014).

Results from a prior study specified conflicting findings regarding the effects of the Big Five personality traits on Internet addiction (Randler, Horzum, \& Vollmer, 2014). Specifically, the study found that agreeable and conscientious students reported lower level of Internet addiction, but no consistent relationship was observed between students addicted to Internet and openness to experiences, extraversion, and neuroticism.

Due to the limited number of such studies, the reasons for the inconsistent findings are not clear (Zhou et al., 2017). These results, how- 
ever, could be influenced by several factors. For example, the use of different instruments to measure personality traits (e.g., full instrument version $v s$ brief measure), the properties of the sample (e.g., cross-sectional vs clinical, experimental), and the different methods used to analyze the data (correlational vs multivariate techniques). Thus, these conflicting outcomes seem to suggest that studying the relation between personality traits and Internet addiction remains a meaningful topic. Additionally, the continuous release of new social networking and Internet applications, as well as the increasing use of simplified computer user-interface require studying their effects on many aspects of individual daily life.

The relationship between self-esteem, considered as a psychological strength that reflects one's overall evaluation of oneself, and Internet addiction has been examined over the past decades (Andreassen et al., 2017; Bleidorn et al., 2016; Hahn, Reuter, Spinath, \& Montag, 2017). In this regard, there is a common view among researchers, which suggests that individuals with lower self-esteem are more predisposed to Internet addiction (Servidio, Gentile, \& Boca, 2018; Yao, He, Ko, \& Pang, 2014). Individuals with low self-esteem, compared to those with higher levels of self-esteem, also tend to spend more time on the Internet using social networking websites. Moreover, this corpus of investigations has found that individuals who score lower on the Big Five personality traits and selfesteem may have greater risks of developing Internet addiction disorder.

Additionally, other studies have been conducted to examine the connection between Internet addiction and other risk factors such as gender, time spent online by the subjects, self-diagnosis of the perceived disorder, and social networking usage (Błachnio et al., 2018; Servidio, 2014; Wang, Ho, Chan, \& Tse, 2015; Widyanto, Griffiths, \& Brunsden, 2011). As discussed earlier, a large and consistent body of research suggests that Internet addiction is a social problem because it is associated with several psychosocial and psychological factors. In this theoretical framework, a recent Italian study (Monacis et al., 2018) has validated the English version (Pontes \& Griffiths, 2015) of the Internet Disorder Scale (IDS). The IDS was designed and developed by modifying the nine criteria for the clinical diagnosis of the Internet Game Disorder (such as salience, mood modification, tolerance, withdrawal symptoms, conflict and relapse) and to adjust them to assess the risk of Internet addiction. The rationale of the IDS is to measure the severity of Internet addiction and its negative impact by only focusing upon a user's online leisure behavior, excluding, for example, academic and/or occupational Internet usage. The validated IDS Italian scale showed adequate psychometric properties, as well as high and positive associations between Internet disorder, Internet gaming disorder, and social media addiction, supporting the idea that Internet addiction works as an umbrella to cover a wide range of online social activities (Monacis et al., 2018).

To the best of our knowledge, the area of creating subgroups of individuals based on Internet usage and personality traits still has to be further studied. The current study seeks to provide empirical evidence relating to this question by exploring the influence of personality factors and psychosocial variables in order to discriminate between the use and abuse of the Internet by specific users.

The results of this investigation may be applied in assessing the prevalence and the nature of Internet addiction disorder among university students, who are often considered a high risk-group (Frangos, Frangos, \& Sotiropoulos, 2011). In addition, the current results may be useful for supporting counselors in developing intervention programs for students with identified Internet addiction risks at the early stage of the disorder. Finally, our find- 
ings contribute to the debate in present literature as to which specific personality traits, or absence thereof, including self-esteem and other variables, may increase Internet addiction risk in university students.

\section{Aim and Research Hypothesis of the Study}

The main aim of the current study is to empirically discriminate the influence of Big Five personality traits, self-esteem, personal experience with Internet usage and well-being at different levels of Internet addiction risk. This study tries to expand the body of knowledge on Internet addiction, by assessing the relative importance of specific predictor variables that could be useful in identifying university students who may be addicted, from those who use the Internet within the norm. According to the above, when information about personality traits, self-esteem, well-being, and time spent online is available, our research hypothesis is to explore which among these are the discriminant predictors that may classify a student as being within the Internet addiction group or not.

\section{Method}

\section{Participants and Procedure}

We recruited a convenience sample of 207 Italian undergraduate university students. The current sample consists of 45 males $(21.7 \%)$ and 162 females $(78.3 \%)$. The participants' ages ranged from 19 to $41(M=25.34, S D=4.39)$ and they majored in three different subject areas (37.2\% scientific, $35.7 \%$ humanistic, and $27.1 \%$ economic). Although the sample is on the smaller side, a previous study, however, has also used similar sample sizes (Kayiş et al., 2016). Additionally, as previous studies have shown, the current study interviewed university students because they are considered at greater risk in developing Internet addiction disorder
(Al-Gamal et al., 2016; Kitazawa et al., 2018; Servidio, 2014; Tian, Bian, Han, Gao, \& Wang, 2017). Before collecting the data, we randomized the order of the instruments to minimize the risk of order bias.

Study participants were recruited during the regular didactic activities, during a break, and while they were at the University library. After we obtained their permission to participate in the study, we informed all participants of the study's anonymity, strict confidentiality, and solely scientific use of all the answers to the questionnaire. Completion of the paper-pencil questionnaire, which was in Italian, took approximately 20 minutes. All the research materials and study procedures were designed according to the Ethics in Human Research (AIP, 2015).

We found that 151 participants (73\%) affirmed staying connected daily to the Internet for 1 to 3 hours, whereas only 56 participants declared using the Internet between 5 and 10 hours per day $(27 \%)$. The majority of the participants $(64.3 \%)$ declared using their own smartphone to establish an Internet connection. Most of them, a good $56.5 \%$, accessed the Internet in order to use Facebook.

\section{Measures}

The Internet Addiction Test (IAT) is a selfreport screener for measuring Internet usage (Young, 1998). We used the translated Italian version of the IAT (Servidio, 2017), which consists of 20 items measured on a 5-point Likert scale ranging from 1 (rarely) to 5 (always). A representative item was: "How often do you block out disturbing thoughts about your life with soothing thoughts of the Internet?" According to Young (2015), the questionnaire measures the extent of an individual's involvement with Internet usage and classifies addictive behavior in terms of an impairment index that ranges from a minimum of 20 to a maximum of 
100. The total score is the sum of the score for each participant's answer. Specifically, the scores indicate the following range of values, with higher scores indicating higher severity of Internet addiction: 0 to $30=$ normal level of Internet usage; 31 to $49=$ mild level of Internet addiction; 50 to $79=$ moderate symptoms, with subjects experiencing occasional or frequent problems with Internet use; and 80 to 100 indicate severe symptoms, where Internet use is causing significant problems in the subject's life (Young, 2015). The Cronbach's alpha score for the internal reliability of the scale for this study was good $(\alpha=.863)$, indicating high consistency.

The Big Five Questionnaire (BFQ) is a 132item self-report measure that aims to examine personality traits identified as extraversion, emotional stability, openness, conscientiousness, and agreeableness (Costa \& McCrae, 1992). The full validated Italian version of the BFQ was used for this study (Caprara et al., 2005). Answers to items are scored on a 5-point Likert scale, ranging from " $1=$ absolutely false for me", to " 5 = absolutely true for me". The score of each Big Five trait was calculated following the procedures described in the BFQ test manual with all the final scores standardized. In the present study, the internal reliability of each Big Five trait was satisfactory (extraversion, $\alpha=.66$; emotional stability, $\alpha=.69$; openness, $\alpha=0.74$; conscientiousness, $\alpha=.70$ and agreeableness, $\alpha=.65$ ).

The Italian Rosenberg Self-Esteem Scale (Prezza, Trombaccia, \& Armento, 1997) was used to measure the subjective feelings of self-value and self-acceptance. Participants rated their answers with 10 statements on the following scale, with higher scores indicating higher selfesteem: 1 (strongly disagree), to 4 (strongly agree). A sample item was: "I feel that I have a number of good qualities". The internal consistency in the sample of this present study was $\operatorname{good}(\alpha=.83)$.
Demographic information as well as self-reports regarding, gender, age, degree course, number of hours spent online per day, well-being in terms of social relationships, and other relevant variables were collected. However, this form was designed by the author, taking into account the previous studies carried out in the field of Internet addiction disorder (Burnay et al., 2015; Monacis et al., 2018; Servidio, 2014; Servidio, 2017).

\section{Data Analysis}

Before conducting the statistical analyses as well the univariate normality assumptions, we checked the data set. As suggested by Kline (2016), all the variables considered for the current analysis had absolute values of skewness $(<3.0)$ and kurtosis $(<8.0)$, thus the assumption of normality was satisfied.

We ran descriptive statistics and Pearson correlation analyses to test the relationship between the variables. Furthermore, we carried out a $t$-test for independent sample to explore the differences between gender, Internet addiction, and self-esteem. Finally, we computed the Cohen's $d$ effect size.

Subsequently, we performed a discriminant analysis in order to determine the best combination of predictor variables for discovering group membership among normal users, mildly impaired users, and users with moderate impairment risk of being addicted to the Internet. The variables entered in the model included the following: time spent online per day, personal and social well-being, Internet addiction, self-esteem, and the Big Five personality traits (extraversion, agreeableness, conscientiousness, emotional stability and openness). For the discriminant analysis, we checked the result of the Box's M test. Finally, as suggested by Field (2013), in order to better validate the results, we conducted a MANOVA with both univariate test and discriminant analysis. All 
the statistical analyses were conducted using SPSS 23.0.

\section{Results}

The IAT's impairment index indicated that 46 (14.9\%) participants reported no Internet addiction symptoms, 130 (63.2\%) participants reported mild symptoms, but they still had control over their Internet usage, and 31 (21.9\%) showed occasional or frequent problems with the Internet (moderate symptoms). For this study, we found no participant affected by severe Internet addiction disorder. The independent $t$-test indicated a significant difference in the scores of Internet addiction and gender $t(205)=3.67, p=.000, d=.63$. The mean values were higher for males $(M=43.58, S D=9.68)$ than for females $(M=37.39, S D=10.08)$. This difference $t(205)=2.54, p=.012, d=.41$ was also confirmed by analyzing the time (hours per day) the participants spent online, where males preferred to stay connected to Internet longer $(M=3.11, S D=1.23)$ than females $(M=2.61$, $S D=1.15)$. However, no significant gender differences were found in self-esteem $t(205)=.90$, $p=.369, d=.14$. There was no statistically significant difference among normal, mildly impaired, and moderately impaired Internet users' index as regards age, $F(2,204)=.14, p=.870$.

The association between the main variables of the current study was investigated using Pearson's correlation, as shown in supplementary Table A.1 (Appendix). Students who had high scores on the Internet addiction questionnaire reported low levels of self-esteem $r(207)=$ $-.28, p=.000$, of conscientiousness $r(207)=-.15$, $p=.032$, and well-being $r(207)=-.18, p=.011$.

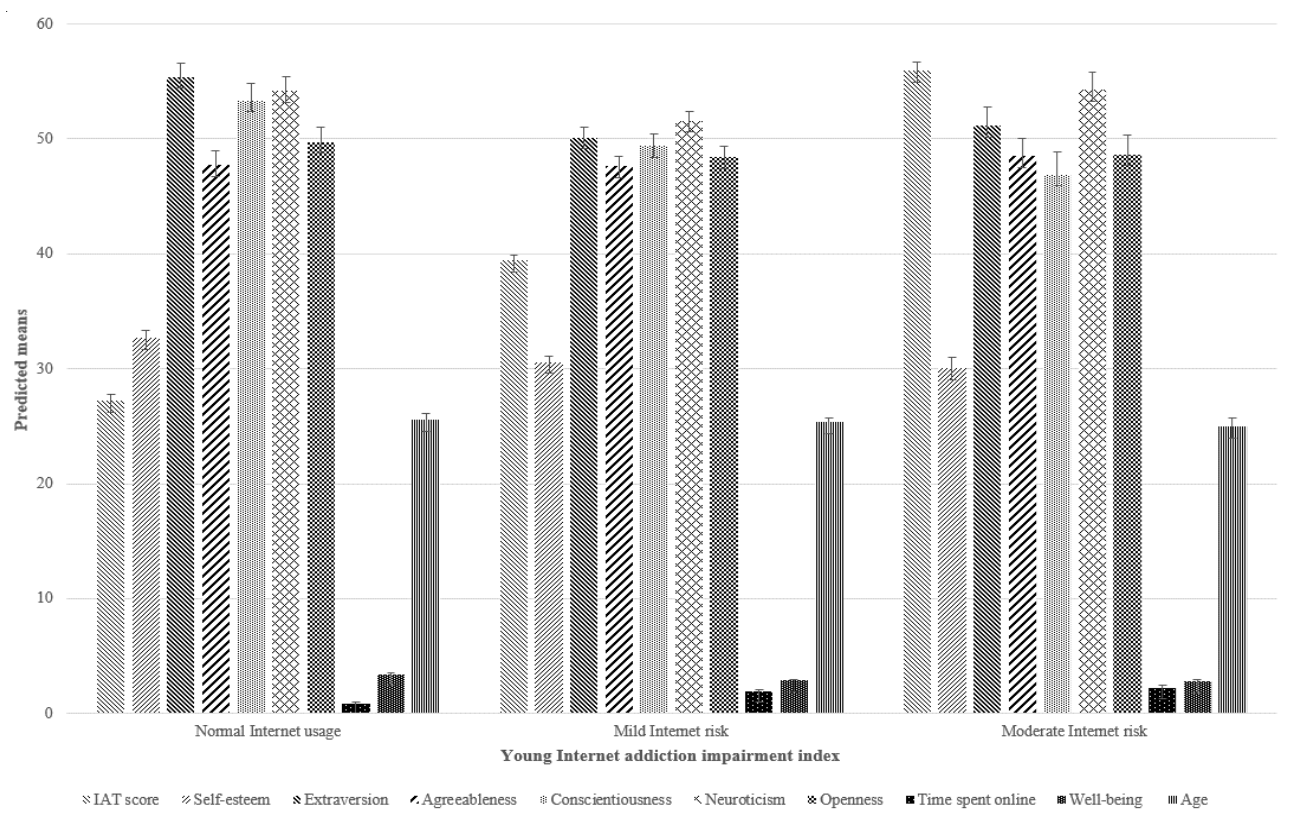

Figure 1 Description of the predicted means across the three distinct categories of Internet users. Bars represent the standard error. 
A between-subjects MANOVA using a Bonferroni-correction yielded a statistically significant difference between the three impairment groups, Pillai's trace $=.976, F(20,392.000)=$ $18.699, p=.000, \eta^{2}=.488$, except for the following variables: agreeableness, emotional stability, openness, and age where the differences between the three groups did not reach statistical significance. For a better illustration of this effect, Figure 1 shows a graphic representation of the predicted mean scores across the three Internet users' groups.

Following the Internet addiction impairment index, weperformed a three-group discriminant analysis on the normal user (reflecting a normal level of Internet usage), the mildly impaired user (indicates the presence of a mild level of Internet addiction), and themoderately impaired user (reflects the presence of a moderate level of Internet addiction). We used the Big Five personality traits, time spent online, well-being, and age as discriminant independent variables (predictor), whereas we used the three main Internet impairment indexes as dependent variables. The results obtained displayed two statistically significant discriminant functions, which indicate that the variables included in the model were able to discriminate among the three groups (Table 1).

The result of the Box's M test indicated that the final value of 151.34 was associated with an alpha level of .05. As a result, there was no violation of the assumption of equality of covariance (Ho, 2014). Table 2 presents the discriminant coefficients for the raw and the standardized form of the variables for each function. The first discriminant function relates to participants, who are in greater risk of being addicted to the Internet, exhibiting lower levels of conscien-

Table 1 Summary of the discriminant functions

\begin{tabular}{lcccccccc}
\hline Function & Eigenvalue & $\begin{array}{c}\text { \% of } \\
\text { variance }\end{array}$ & $\begin{array}{c}\text { Canonical } \\
\text { correlation }\end{array}$ & $\begin{array}{c}\text { Canonical } \\
\mathrm{R}^{2}\end{array}$ & $\begin{array}{c}\text { Wilks' } \\
\text { Lambda }\end{array}$ & $\begin{array}{c}\text { Chi- } \\
\text { square }\end{array}$ & $d f$ & $p$ \\
\hline 1 & 4.326 & 97.7 & .901 & .811 & .170 & 353.372 & 20 & .000 \\
2 & .104 & 2.3 & .307 & .094 & .906 & 19.696 & 9 & .020 \\
\hline
\end{tabular}

Table 2 Raw and standardized discriminant function coefficients

\begin{tabular}{lccccc}
\hline \multirow{2}{*}{ Measured variable } & \multicolumn{2}{c}{ Raw score coefficient } & & \multicolumn{2}{c}{ Standardized coefficient } \\
\cline { 2 - 3 } \cline { 2 - 3 } \cline { 5 - 6 } IAT score & Function 1 & Function 2 & & Function 1 & Function 2 \\
Self-esteem & .225 & .048 & & 1.047 & .225 \\
Extraversion & .042 & .055 & & .211 & .276 \\
Agreeableness & -.015 & .038 & & -.139 & .359 \\
Conscientiousness & .003 & .002 & & .024 & .016 \\
Emotional stability & -.009 & .010 & & -.104 & .116 \\
Openness & .002 & .062 & & .020 & .563 \\
Time spent online per day & .017 & .016 & & .173 & .162 \\
Well-being & .001 & -.571 & & .001 & -.614 \\
Age & -.030 & .249 & & -.032 & .268 \\
Constant & -.030 & -.024 & & -.133 & -.104 \\
\hline
\end{tabular}


tiousness and extraversion, and having moderate values of self-esteem, openness, and age. This dimension accounts for the largest percentage of explained variance in the canonical correlate ( $97.7 \%$ of the total).

The second dimension relates to cases with a weak risk of being addicted to the Internet, where heavy Internet usage is not a priority, exhibiting lower time spent online per day; emotional stability, extraversion, self-esteem and age were the most strongly weighted variables, whereas conscientiousness, openness and well-being were also important discriminant factors. This dimension accounts for $2.3 \%$ of the total explained canonical correlate variance.

The two latent constructs represented by the discriminant functions can be interpreted with respect to the structure coefficients as shown in Table 3. For the first function, higher levels of the latent variable are indicated by a higher Internet addiction score and more time spent online per day. This factor appears to represent an Internet use/abuse. The second latent construct is indicated primarily by greater emotional stability, extraversion, self-esteem, openness, well-being, agreeableness, and conscientiousness, and by lower levels of time spent online per day, Internet addiction score and age. It appears to represent the area of personality functioning related to Internet use.

Figure $2 \mathrm{a}$ shows the difference in centroids values, which are relatively substantial along the first function (Internet use/abuse), where the three groups are differentiated. Those who use Internet within the norm reported a better behavioral strategy toward the Internet, whereas those with a moderate level of impairment showed a relatively unhealthy adaptation to the Internet with higher risk of becoming addicted. Then, those with mild impairment reported a midrange adaptation toward Internet usage.

Looking at the second function (personality functioning related to Internet), the differences in centroids values are much more modest. Participants who are normal Internet users appear to have a stable personality functioning, compared to those who have a moderate level of Internet addiction; whereas, those who are in the midrange group appear to care somewhat less about Internet addiction. The midrange position can be interpreted as being sort of separated from the other two groups. Figure $2 b$ offers a visual representation of the centroids to better discriminate the groups' membership.

Table 3 Structure coefficients (structural matrix)

\begin{tabular}{lcc}
\hline \multirow{2}{*}{ Measured variable } & \multicolumn{2}{c}{ Structure coefficient } \\
\cline { 2 - 3 } & Function 1 & Function 2 \\
\hline IAT score & .953 & -.043 \\
Emotional stability & -.018 & .525 \\
Time spent online per day & .210 & -.523 \\
Extraversion & -.053 & .449 \\
Self-esteem & -.083 & .344 \\
Openness & -.013 & .279 \\
Well-being & -.087 & .277 \\
Agreeableness & .006 & .256 \\
Conscientiousness & -.089 & .152 \\
Age & -.020 & .038 \\
\hline
\end{tabular}



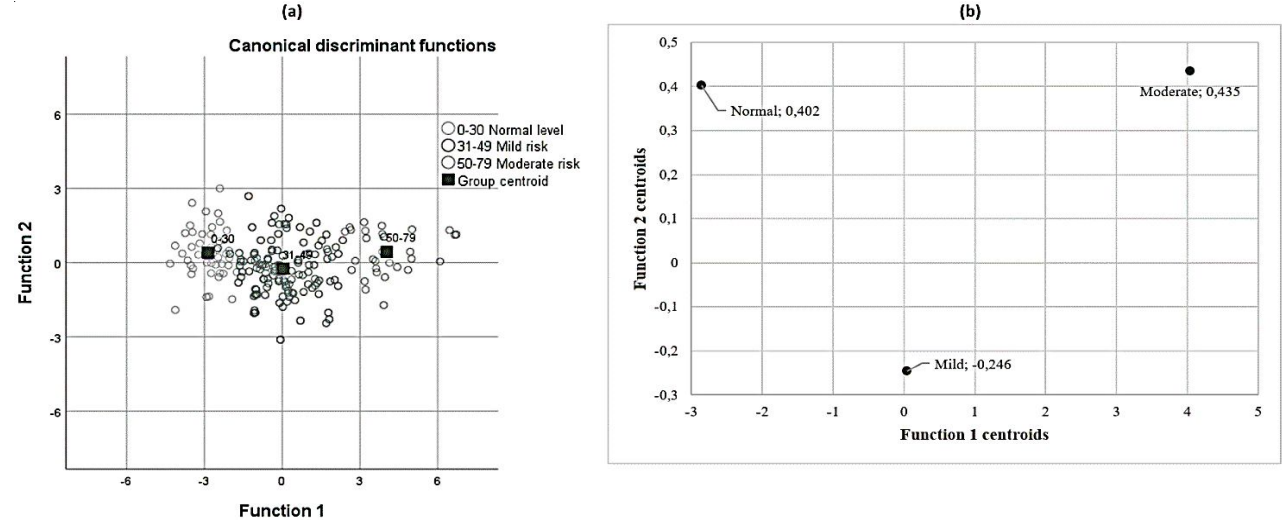

Figure 2 Combined discriminant group plot (a) and simplified axis scaled combined group plot (b)

It is also important to consider the correctness of the model classifying the participants in their group. In that sense, the prediction made by the model had a good percentage of success, with $92.80 \%$ of all cases classified correctly. This value ranges from $22.22 \%$ ( 46 of 46 cases) for those who are not addicted to Internet, to $55.55 \%$ (115 of 130 cases) for those who have a mild risk of Internet addiction and 14.97\% (31 of 31 cases) for those who were classified as addicted to Internet moderately.

\section{Discussion}

The current study has explored the role of personality traits of some empirically-discriminate groups of Internet risk users, categorized as normal, mildly addicted, and moderately addicted to the Internet. Current studies in this field tend to replicate statistical analysis methods such as correlational, linear, and multiple regression analyses. We adopted the discriminant analysis method with the aim of generating membership from a set of predictors.

Correlation analysis showed that self-esteem, conscientiousness, well-being, and gender were negatively associated with Internet addiction test, whereas time spent online per day was positively linked. This pattern was similar in other studies as well (Kuss et al., 2014; Servidio, 2014). It was evident that the risk of being addicted to the Internet is associated with lower levels of planning, organizing, and discipline in the user's behavior, as well as lower levels of self-esteem and well-being.

The predictor variables that contributed in the discriminant analysis model were items related to the Big Five personality traits, self-esteem, well-being, and age. The resulting analysis yielded two canonical dimensions. The first profile explained more variance and included participants with lower levels of extraversion, conscientiousness and age, and moderate values of self-esteem. The second profile included participants who reported less involvement with Internet activities in general and greater emotional stability, extraversion, self-esteem, and well-being. It can be argued that personality traits influence and predispose a person's behavior in the social and virtual context. From this perspective, personality factors are important because they can be used to understand 
the complexity of human behavior. This knowledge is particularly important in current society where people use Internet technologies every day.

The results show that a decrease in the involvement of each personality trait, self-esteem, and well-being, leads to a rise in the time spent online, and increases the risk of Internet addiction. In explaining these results, it can be affirmed that emotional stability, openness, and extraversion showed a higher discriminant effect, while conscientiousness and self-esteem, as well as agreeableness and well-being, were moderately involved. With the exception of openness, the results of the Big Five personality traits are consistent with the outcomes of a recent literature review (Kayiş et al., 2016).

For the purpose of the current study, however, it is important to underline that emotional stability, extraversion and self-esteem appear to be important dimensions that protect people against Internet addiction. In other words, individuals with higher levels of emotional stability, extraversion and self-esteem are more predisposed to establishing face-to-face communication with others in real-life contexts because they have good self-control, lower anxiety, and show confident levels of self-awareness. Other previous studies are in line with these findings (Kayiş et al., 2016, for a review). According to the Big Five personality model, people with low emotional stability tend to experience increased levels of stress and interpersonal conflicts, and are also unable to cope with stressful events. Extraversion represents an important trait because it relates to an individual's enthusiastic attitude towards social situations involving characteristics such as sociability, activeness, decisiveness, and positive emotionality. On the contrary, people with low levels of extraversion use the Internet more frequently, thus increasing the risk of becoming addicted. Thus, introverted people prefer to use the Internet because they find it easier to establish satisfying and close interpersonal relationships in the virtual arena.

Self-esteem is another relevant predictor of Internet addiction and has been identified as a risk factor. People with lower levels of self-esteem scored higher on Internet addiction risks (Hahn et al., 2017; Servidio et al., 2018). The current findings corroborate the role of self-esteem, which can serve as a buffer to Internet addiction in the sense that people with lower self-esteem could use the Internet as a strategy in the attempt to improve their self-esteem (Zhang et al., 2015).

Finally, time spent online per day was negatively related to Internet addiction and appears to be another important variable for predicting the risk of Internet addiction. In the current study, we found that limiting the number of hours spent online per day by individuals reduces the risk of Internet addiction. This result is consistent with other previous outcomes, which stress the importance of monitoring the time spent online to avoid long Internet sessions (Servidio, 2014; Wang et al., 2015). Although the majority of the studies are crosssectional, time spent online could be an indicator of increasing tolerance, which is a criterion for substance dependence. Moreover, the fact that people spend more of their time online means that they opt out of engaging in alternative social activities with friends and significant others, and this could be an impairment symptom (Kuss et al., 2014).

By considering the discriminant plot, it is important to note that the first function shows a good discriminant profile (Internet use/abuse) among the three impairments risks, whereas the second function (personality functioning related to Internet) indicates that the three groups are relatively close to each other. This result could be interpreted that any one risk factor depends on other aspects related to personal and social factors. According to Li et al. (2017), it is uncommon to find that two latent profiles 
have identical levels in one dimension but different levels of some indicators in another dimension. In the present study, although users with moderate profiles have higher risks of becoming addicted to the Internet, compared to those with normal profiles, the difference in their level of impairment is modest along the second function, which is related to personality traits, self-esteem, and well-being. The normal and moderate profiles appear to be separated by a mild risk profile. These findings may suggest that all three profiles are relatively related to each other. However, if adolescents experience the moderate (vs. normal and mild) influence of multiple risk factors, their level of Internet addiction could increase.

To sum up, the current results suggest that the discriminant analysis allows the discrimination of the influence of specific personality traits, the role of self-esteem, and time spent online on the three groups of Internet users. It is evident that the question regarding the positive or negative psychological effects of Internet use, particularly on adolescents, needs further research. Identifying the grouping of Internet users may support researchers in making comparisons among Internet users and could be useful in defining psychosocial profiles, to avoid having to classify people as good or bad Internet users.

\section{Limitations and Future Research}

The current study has some limitations. First, the study is based on a sample of undergraduate students, who are not fully representative of the whole population of Internet users. Future research should consider the importance of designing longitudinal studies to examine the effects of how personality traits can also vary in relation to the development of new and advanced technological applications. Further studies could also explore the differences in Internet risks among participants with different educational backgrounds. Second, we collected data via participants' self-report methodology, whose results may be affected by social desirability. Future studies could replicate the current discriminant model to test the validity of the current findings. In addition, it would also be interesting to explore the possibility of applying other similar statistical methods, such as cluster analysis, which is an interdependence technique and is based on a posteriori grouping, where a set of variables may be optimally grouped. The results would be useful to differentiate the types of normal/addicted users in relation to specific variables. Third, the variable that measured the time spent online was built by asking participants about the time spent daily on the Internet. They could have had inaccurate time-perceptions of the time spent using social media technologies (Wolniewicz, Tiamiyu, Weeks, \& Elhai, 2018). Fourth, we found no severe Internet addicts among the participants, but only those with mild and moderate risks. This result is common among university students. From this perspective, a larger sample of participants as well as a balance in the presence of males and females should reduce this limitation.

\section{Conclusion}

Our findings indicate two distinct dimensions, which are useful in predicting whether a person can be classified as addicted to Internet, demonstrating that different persons can share and exhibit the same behavior, indicating the importance of carefully analyzing psychosocial problems. These results advance our understanding of the association between Internet addiction, demographic factors, and personality traits, insofar as these factors could be areas for prevention. A clear understanding of this association may provide precise measures that could help prevent Internet addiction. Despite the limitations mentioned, the results of the current 
study can provide important implications for policy for counselors, individuals, and researchers, and suggest some possible intervention programs aimed at preventing the risk of Internet addiction. From this perspective, a possible strategy for preventing the risk of Internet addiction could be important in the creation of educational programs devoted to supporting Internet users so that they become more selfconfident and emotionally stable in specific areas of their personal life.

\section{References}

Al-Gamal, E., Alzayyat, A., \& Ahmad, M. M. (2016). Prevalence of Internet addiction and its association with psychological distress and coping strategies among university students in Jordan: Prevalence of Internet addiction and its association with psychological distress and coping strategies among university students in Jordan. Perspectives in Psychiatric Care, 52(1), 49-61. https://doi.org/10.1111/ppc. 12102

Andreassen, C. S., Pallesen, S., \& Griffiths, M. D. (2017). The relationship between addictive use of social media, narcissism, and self-esteem: Findings from a large national survey. Addictive Behaviors, 64, 287-293. https://doi.org/10.1016/j.addbeh.2016. 03.006

Błachnio, A., Przepiórka, A., Wołońciej, M., Bassam Mahmoud, A., Holdoš, J., \& Yafi, E. (2018). Loneliness, friendship, and Facebook intrusion. A study in Poland, Slovakia, Syria, Malaysia, and Ecuador. Studia Psychologica, 60(3), 183-194. https://doi.org/10. $21909 /$ sp.2018.03.761

Bleidorn, W., Arslan, R. C., Denissen, J. J. A., Rentfrow, P. J., Gebauer, J. E., Potter, J., \& Gosling, S. D. (2016). Age and gender differences in self-esteem a cross-cultural window. Journal of Personality and Social Psychology, 111(3), 396-410. https://doi.org/ 10.1037/pspp0000078

Burnay, J., Billieux, J., Blairy, S., \& Larøi, F. (2015). Which psychological factors influence Internet addiction? Evidence through an integrative model. Computers in Human Behavior, 43, 28-34. https:/ /doi.org/10.1016/j.chb.2014.10.039

Caprara, G. V., Barbaranelli, C., \& Borgogni, L. (2005) $B F Q$ : Big Five Questionnaire (2nd ed.). Firenze: O.S. Organizzazioni Speciali.

Chou, W.-P., Ko, C.-H., Kaufman, E. A., Crowell, S. E., Hsiao, R. C., Wang, P.-W., ... \& Yen, C.-F. (2015).
Association of stress coping strategies with Internet addiction in college students: The moderating effect of depression. Comprehensive Psychiatry, 62, 2733. https://doi.org/10.1016/j.comppsych.2015.06. 004

Chwaszcz, J., Lelonek-Kuleta, B., Wiechetek, M., Niewiadomska, I., \& Palacz-Chrisidis, A. (2018). Personality traits, strategies for coping with stress and the level of Internet addiction - a study of Polish secondary-school students. International Journal of Environmental Research and Public Health, 15(5), 987. https://doi.org/10.3390/ijerph15050987

Costa, P. T., \& McCrae, R. R. (1992). Four ways five factors are basic. Personality and Individual Differences, 13(6), 653-665. https://doi.org/10.1016/ 0191-8869(92)90236-I

Field, A. (2013). Discovering statistics using IBM SPSS statistics (3rd ed.). Sage.

Frangos, C. C., Frangos, C. C., \& Sotiropoulos, I. (2011). Problematic Internet use among Greek university students: An ordinal logistic regression with risk factors of negative psychological beliefs, pornographic sites, and online games. Cyberpsychology, Behavior, and Social Networking, 14(1-2), 51-58. https:// doi.org/10.1089/cyber.2009.0306

Gentile, A., Servidio, R., Caci, B., \& Boca, S. (2018). Social stigma and self-esteem as mediators of the relationship between Body Mass Index and Internet addiction disorder. An exploratory study. Current Psychology. https://doi.org/10.1007/s12144-0180054-x

Hahn, E., Reuter, M., Spinath, F. M., \& Montag, C. (2017). Internet addiction and its facets: The role of genetics and the relation to self-directedness. Addictive Behaviors, 65, 137-146. https://doi.org/ 10.1016/j.addbeh.2016.10.018

Ho, R. (2014). Handbook of univariate and multivariate data analysis with IBM SPSS (Second edition). Boca Raton: CRC Press, Taylor \& Francis Group.

Hwang, J., Choi, J.-S., Gwak, A., Jung, D., Choi, S.-W., Lee, J., ... \& Kim, D. (2014). Shared psychological characteristics that are linked to aggression between patients with Internet addiction and those with alcohol dependence. Annals of General Psychiatry, 13(1), 6. https://doi.org/10.1186/1744-859X-13-6

Kayiş, A. R., Satici, S. A., Yilmaz, M. F., Şimşek, D., Ceyhan, E., \& Bakioğlu, F. (2016). Big five-personality trait and internet addiction: A meta-analytic review. Computers in Human Behavior, 63, 35-40. https://doi.org/10.1016/j.chb.2016.05.012

Kitazawa, M., Yoshimura, M., Murata, M., SatoFujimoto, Y., Hitokoto, H., Mimura, M., ... \& Kishimoto, T. (2018). Associations between problematic Internet use and psychiatric symptoms among university students in Japan: Problematic 
Internet use among students. Psychiatry and Clinical Neurosciences, 72(7), 531-539. https://doi.org/ $10.1111 /$ pcn. 12662

Kline, R. B. (2016). Principles and practice of structural equation modeling (Fourth edition). New York: The Guilford Press.

Kuss, D., Griffiths, M. D., Karila, L., \& Billieux, J. (2014). Internet addiction: A systematic review of epidemiological research for the last decade. Current Pharmaceutical Design, 20(25), 4026-4052.

Kuss, D. J., Shorter, G. W., van Rooij, A. J., van de Mheen, D., \& Griffiths, M. D. (2014). The Internet addiction components model and personality: Establishing construct validity via a nomological network. Computers in Human Behavior, 39, 312-321. https://doi.org/10.1016/j.chb.2014.07.031

Li, D., Li, X., Zhao, L., Zhou, Y., Sun, W., \& Wang, Y (2017). Linking multiple risk exposure profiles with adolescent Internet addiction: Insights from the person-centered approach. Computers in Human Behavior, 75, 236-244. https://doi.org/10.1016/j.chb. 2017.04 .063

Lyvers, M., Karantonis, J., Edwards, M. S., \& Thorberg, F. A. (2016). Traits associated with internet addiction in young adults: Potential risk factors. Addictive Behaviors Reports, 3, 56-60. https://doi.org/ 10.1016/j.abrep.2016.04.001

McNicol, M. L., \& Thorsteinsson, E. B. (2017). Internet addiction, psychological distress, and coping responses among adolescents and adults. Cyberpsychology, Behavior, and Social Networking, 20(5), 296-304. https://doi.org/10.1089/cyber.2016. 0669

Monacis, L., de Palo, V., Griffiths, M. D., \& Sinatra, M. (2017). Exploring individual differences in online addictions: The role of identity and attachment. International Journal of Mental Health and Addiction, 15(4), 853-868. https://doi.org/10.1007/ s1 1469-017-9768-5

Monacis, L., Sinatra, M., Griffiths, M. D., \& de Palo, V. (2018). Assessment of the Italian version of the Internet Disorder Scale (IDS-15). International Journal of Mental Health and Addiction, 16(3), 680691. https://doi.org/10.1007/s11469-017-9823-2

Nie, J., Li, W., Wang, P., Wang, X., Wang, Y., \& Lei, L. (2019). Adolescent type D personality and social networking sites addiction: A moderated mediation model of restorative outcomes and affective relationships. Psychiatry Research, 271, 96-104. https:/ /doi.org/10.1016/j.psychres.2018.11.036

Öztürk, C., Bektas, M., Ayar, D., Özgüven Öztornacı, B., \& Yağc1, D. (2015). Association of personality traits and risk of Internet addiction in adolescents Asian Nursing Research, 9(2), 120-124. https:// doi.org/10.1016/j.anr.2015.01.001
Pontes, H. M., \& Griffiths, M. D. (2015). The development and psychometric evaluation of the internet disorder scale (IDS-15). Addictive Behaviors. https:/ /doi.org/10.1016/j.addbeh.2015.09.003

Prezza, M., Trombaccia, F. R., \& Armento, L. (1997) La scala dell'autostima di Rosenberg: Traduzione e validazione Italiana. [The Rosenberg Self-Esteem Scale: Italian translation and validation.]. Bollettino di Psicologia Applicata, 223, 35-44.

Randler, C., Horzum, M. B., \& Vollmer, C. (2014). Internet addiction and its relationship to chronotype and personality in a Turkish university student sample. Social Science Computer Review, 32(4), 484-495. https://doi.org/10.1177/ 0894439313511055

Sahraian, A., Hedayati, S. B., Mani, A., \& Hedayati, A. (2016). Internet addiction based on personality characteristics in medical students. Shiraz EMedical Journal, 17(10). https://doi.org/10.17795/ semj41149

Servidio, R. (2014). Exploring the effects of demographic factors, Internet usage and personality traits on Internet addiction in a sample of Italian university students. Computers in Human Behavior, 35, 85-92. https://doi.org/10.1016/j.chb.2014. 02.024

Servidio, R. (2017). Assessing the psychometric properties of the Internet Addiction Test: A study on a sample of Italian university students. Computers in Human Behavior, 68, 17-29. https://doi.org/ 10.1016/j.chb.2016.11.019

Servidio, R., Gentile, A., \& Boca, S. (2018). The mediational role of coping strategies in the relationship between self-esteem and risk of Internet addiction. Europe's Journal of Psychology, 14(1), 176187. https://doi.org/10.5964/ejop.v14i1.1449

Tian, Y., Bian, Y., Han, P., Gao, F., \& Wang, P. (2017). Associations between psychosocial factors and generalized pathological internet use in Chinese university students: A longitudinal cross-lagged analysis. Computers in Human Behavior, 72, 178-188. https: //doi.org/10.1016/j.chb.2017.02.048

Wang, C.-W., Ho, R. T. H., Chan, C. L. W., \& Tse, S. (2015). Exploring personality characteristics of Chinese adolescents with internet-related addictive behaviors: Trait differences for gaming addiction and social networking addiction. Addictive Behaviors, 42, 32-35. https://doi.org/10.1016/j.addbeh. 2014.10 .039

Widyanto, L., Griffiths, M. D., \& Brunsden, V. (2011). A psychometric comparison of the Internet Addiction Test, the Internet-Related Problem Scale, and self-diagnosis. Cyberpsychology, Behavior, and Social Networking, 14(3), 141-149. https://doi.org/ $10.1089 /$ cyber. 2010.0151 
Wolniewicz, C. A., Tiamiyu, M. F., Weeks, J. W., \& Elhai, J. D. (2018). Problematic smartphone use and relations with negative affect, fear of missing out, and fear of negative and positive evaluation. Psychiatry Research, 262, 618-623. https://doi.org/ 10.1016/j.psychres.2017.09.058

Yan, W., Li, Y., \& Sui, N. (2014). The relationship between recent stressful life events, personality traits, perceived family functioning and Internet addiction among college students: An interaction of life stress with psychoticism. Stress and Health, 30(1), 3-11. https://doi.org/10.1002/smi.2490

Yao, M. Z., He, J., Ko, D. M., \& Pang, K. (2014). The influence of personality, parental behaviors, and selfesteem on Internet addiction: A study of Chinese college students. Cyberpsychology, Behavior, and Social Networking, 17(2), 104-110. https://doi.org/ $10.1089 /$ cyber.2012.0710

Young, K. (2015). The evolution of Internet Addiction Disorder. In C. Montag \& M. Reuter (Eds.),
Internet Addiction (pp. 3-17). Cham: Springer International Publishing. https://doi.org/10.1007/9783-319-07242-5 1

Young, K. S. (1998). Internet addiction: The emergence of a new clinical disorder. CyberPsychology \& Behavior, 1(3), 237-244. https://doi.org/10.1089/ cpb.1998.1.237

Zhang, Y., Mei, S., Li, L., Chai, J., Li, J., \& Du, H. (2015). The relationship between impulsivity and Internet addiction in Chinese college atudents: A moderated mediation analysis of meaning in life and self-esteem. PLOS ONE, 10(7), e0131597. https:// doi.org/10.1371/journal.pone.0131597

Zhou, Y., Li, D., Li, X., Wang, Y., \& Zhao, L. (2017). Big five personality and adolescent Internet addiction: The mediating role of coping style. Addictive Behaviors, 64, 42-48. https://doi.org/10.1016/ j.addbeh.2016.08.009 


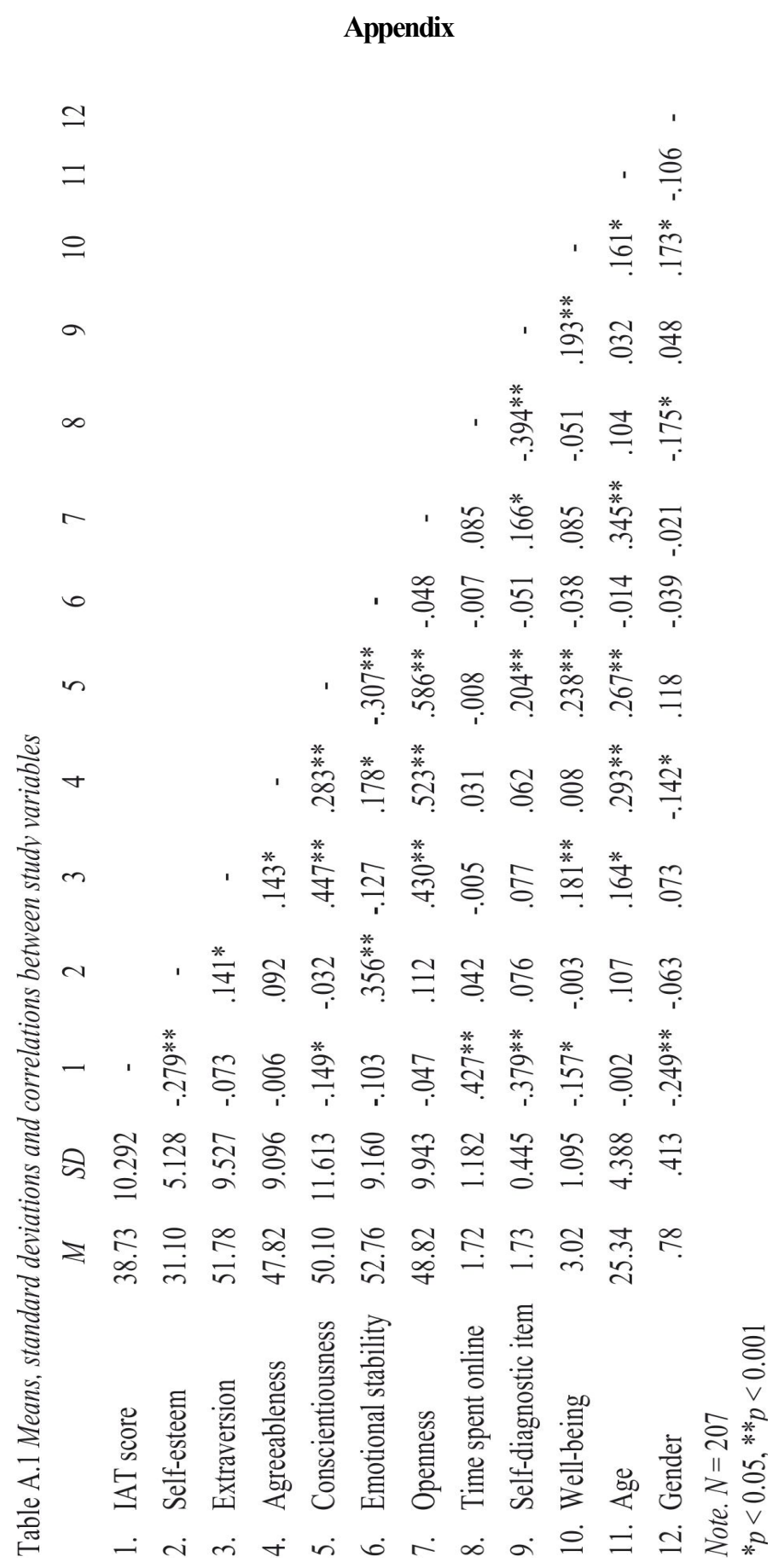

